\title{
Motor conduction velocity in the human spinal cord: slowed conduction in multiple sclerosis and radiation myelopathy
}

\author{
SJ SNOOKS, M SWASH \\ From St Mark's Hospital, and The London Hospital, London, UK
}

SUMMARY Transcutaneous electrical stimulation of the central nervous system was used to measure motor conduction velocity in the human spinal cord in 21 subjects aged 22 to 75 years (mean 55 years), none of whom had neurological disease. The motor conduction velocity between the sixth cervical (C6) and first lumbar (L1) vertebral levels was $67.4 \pm 9.1 \mathrm{~m} / \mathrm{s}$. This probably represents conduction velocity in the corticospinal tracts. In these subjects the motor conduction velocity in the cauda equina, between the first lumbar (L1) and fourth lumbar (L4) vertebral levels, was $57.9 \pm 10.3 \mathrm{~m} / \mathrm{s}$. In four of five patients with multiple sclerosis, all with corticospinal signs in the legs, motor conduction velocity between C6 and L1 was slowed (41.8 $\pm 16 \cdot 8 \mathrm{~m} / \mathrm{s})$, but cauda equina conduction was normal $(55.8 \pm 7.8 \mathrm{~m} / \mathrm{s})$. Similar slowing of spinal cord motor conduction was found in a patient with radiation myelopathy. This method should provide a relevant, simple clinical test in patients with spinal cord disease.

The scope of electrophysiological investigation of the central nervous system is limited and, in particular, there is no method available for assessment of the motor system in the spinal cord. We have devised a method for measurement of the motor conduction velocity in the human spinal cord by adapting the technique of transcutaneous electrical stimulation of the CNS devised by Merton and Morton. ${ }^{2}$ This method promises to be of considerable practical value in clinical practice. It also enables motor conduction to be assessed in the cauda equina. In this report we present our results in normal subjects and show that motor conduction velocity in the spinal cord is slowed in some patients with demyelinating diseases.

\section{Methods}

We stimulated the spinal cord and cauda equina at C6, L1 and $L 4$ vertebral levels respectively using a device consisting of two $1 \mathrm{~cm}$ diameter saline-soaked pad electrodes mounted $5 \mathrm{~cm}$ apart. We have not found it possible, so far, to stimulate reliably the motor roots of the cauda equina at

Address for reprint requests: Dr M Swash, The London Hospital, London E1 1BB, UK.

Received 14 August 1984 and in revised form 19 November 1984. Accepted 23 November 1984 a lower vertebral level than L4. The subject lay in the left lateral position and an earth electrode was applied to the right upper thigh. The stimulating electrodes, mounted on a holder, were pressed firmly against the skin overlying the spine at the appropriate level, in the midline, with the cathode caudally. Single shocks of 800-1500 volts, decaying with a time constant of $50 \mu \mathrm{s}$, were used. ${ }^{2}$ The stimulus triggered the oscilloscope of a Medelec MS6 EMG apparatus through the delay line. Muscle contraction was observed in response to the stimulus in the paravertebral and abdominal muscles and in the muscles of the buttocks and legs. This was perceived as a jolt, but was not painful. We recorded the muscle response from the pelvic floor muscles, innervated by the S3-4 myotomes ${ }^{3}$ using intraanal surface electodes or, as in cases 4 and 6 (table), from tibialis anterior (L4-5 myotomes). Selection of a lower limb muscle, for example tibialis anterior, excludes the sacral component of the spinal cord from the measurement, but does allow lateralisation of the response. The intraanal recording electrode consisted of a modified telephone jack placed in the anal canal adjacent to the external anal sphincter muscle ${ }^{2}$ or a pair of electrodes mounted on the tip of a rubber finger stall held digitally in the anal canal against the puborectalis bar. ${ }^{4}$ The latter technique gave the better result (fig 1).

The latencies from transcutaneous stimulation at C6, L1 and L4 vertebral levels, with a constant recording site, were used to determine latencies between $\mathrm{C} 6$ and $\mathrm{L} 1$, representing the length of the spinal cord from $\mathrm{C} 6$ to the conus medullaris, and between $\mathrm{L} 1$ and $\mathrm{L} 4$, representing the rostral portion of the motor roots in the cauda equina. After 


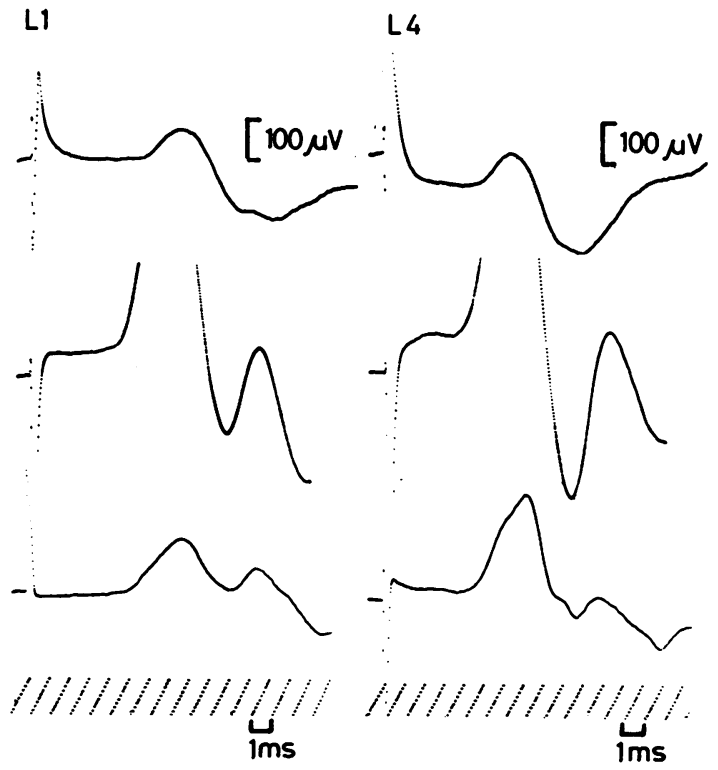

Fig 1 Compound muscle action potentials recorded after stimulation at L1 and L4 vertebral levels in the external anal sphincter (top), puborectalis (middle) and periurethral striated sphincter musculature (bottom); all recordings with surface electrodes (see text). The sharpest takeoff is obtained from the puborectalis muscle using a digitally-directed intra-anal recording method. ${ }^{4}$ The latencies to these three muscles differ, reflecting the differing lengths of the nerves innervating them. ${ }^{4}$

measurement of the inter-electrode distances the motor conduction velocities in the cord (C6-L1) and cauda equina (L1-L4) were calculated. All latency measurements (figs 2 and 3) were made from the onset of the stimulus artefact to the take-off of the compound muscle action potential. The shortest latencies were obtained by adjusting the stimulus voltage so that supramaximal shocks were delivered. These latencies thus represent fastest motor conduction in the cord, and cauda equina. The Wilcoxon rank sum test was used to compare the results in the different groups.

The question of whether the cathode or the anode was the active stimulating electrode was investigated in preliminary experiments. No difference in motor latency was observed following spinal cord or cauda equina stimulation when the stimulus was applied with the anode, or the cathode, placed caudally on the spinal cord.

\section{Patients}

Twenty one normal subjects, aged 22 to 75 years (mean 55 years) were studied. The puborectalis muscle response was used for latency measurements in all but two, in whom the tibialis anterior response was used (fig 1). None of these subjects had suffered from any neurological disorder or from diabetes mellitus. They had been referred to the

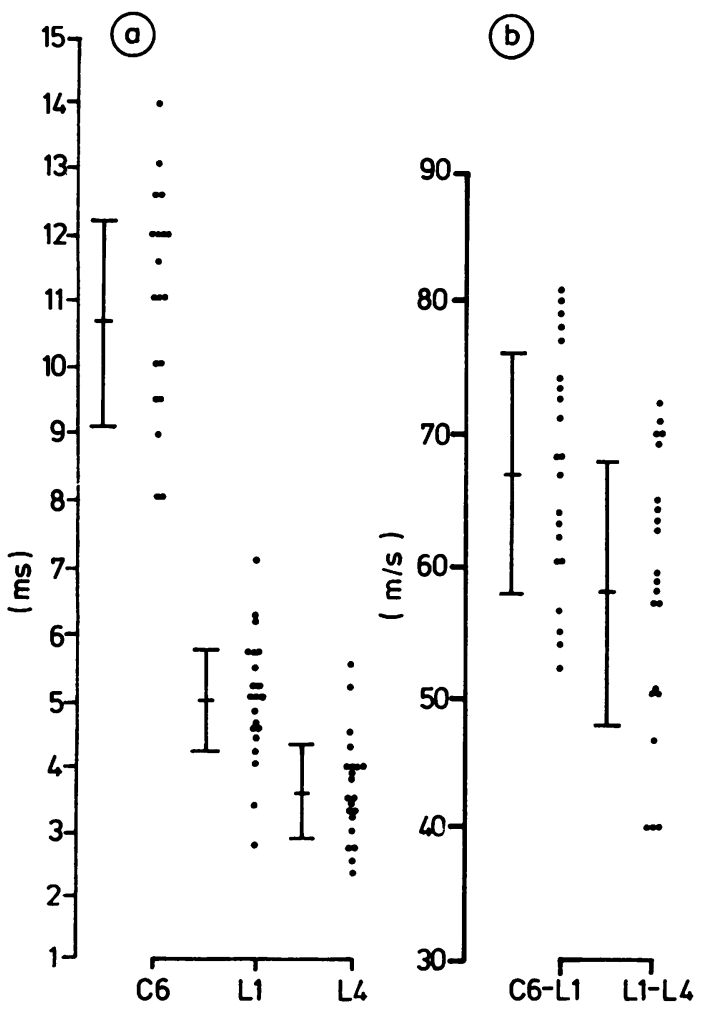

Fig 2 Motor latency $(A)$ and conduction velocity (b) results in 21 normal subjects. Means and standard deviations are displayed to the left of the points. (A) Motor latencies from stimulation at $C 6, L 1$ and L4 vertebral levels, recording the evoked compound muscle action potential in the puborectalis muscle of the pelvic floor. In two subjects the response after C6 stimulation was recorded from the tibialis muscle and these results are not shown. (B) Motor conduction velocities between $C 6$ and $L 1$, and $L 1$ and $L 4$.

Department of Physiology at St Mark's Hospital for evaluation of minor ano-rectal disorders, for example haemorrhoids, constipation. Informed consent was obtained from each subject.

We used the same method in five patients with multiple sclerosis, and in one patient with radiation myelopathy that followed treatment of a bronchial adenocarcinoma (table). In the latter patient there was a severe, progressive, spastic paraparesis with a motor and sensory level at T6. Myelography and CT scanning of this region showed an atrophic spinal cord; the CSF protein was slightly raised $(0.9 \mathrm{~g} / \mathrm{l})$. All the patients with multiple sclerosis had signs of corticospinal disease, usually asymmetrical, in their legs. In all five patients the diagnosis was clinically definite according to the criteria proposed by McDonald. ${ }^{5}$ In case 2 the clinical features suggested lesions in the brain stem and optic nerves, rather than the spinal cord. None of these patients was incontinent. 


\section{Results}

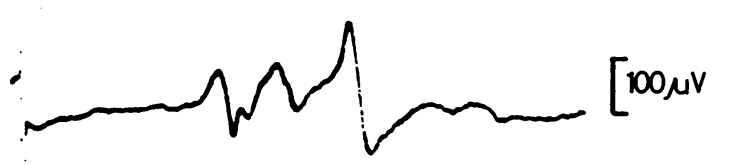

The motor conduction velocities in the spinal cord and cauda equina in the normal subjects are shown, with the latencies from $\mathrm{C} 6, \mathrm{~L} 1$ and $\mathrm{L} 4$ stimulation points in fig 2 , and examples of the responses recorded in the puborectalis muscle are shown in fig 3 . The muscle response recorded after C6 (spinal cord) stimulation was more complex than that recorded after L1 and L2 (cauda equina) stimulation. In the normal subjects the mean motor conduction velocity in the spinal cord, between $\mathrm{C} 6$ and $\mathrm{L} 1$ vertebral levels was $67.4 \pm 9 \cdot 1 \mathrm{~m} / \mathrm{s}$. In these subjects the motor conduction velocity in the cauda equina, between the L1 and L4 vertebral levels, was $57.9 \pm 10.3 \mathrm{~m} / \mathrm{s}$. Mean motor conduction velocity in the spinal cord in the normal subjects was thus about $10 \mathrm{~m} / \mathrm{s}$ faster than in the cauda equina $(p<0.01)$. Although there was a trend for motor conduction velocity to decrease with age in both the spinal cord and the cauda equina the correlation coefficients for these trends were not significant (spinal cord $r=$ $0 \cdot 1, p>0 \cdot 1$; cauda equina $r=-0 \cdot 2, p>0 \cdot 1)$.

In the five patients with multiple sclerosis the motor conduction velocity in the spinal cord, between $\mathrm{C} 6$ and $\mathrm{L} 1$ levels, was slower than in the normal subjects $(41.8 \pm 16.8 \mathrm{~m} / \mathrm{s} ; \mathrm{p}<0.001)$, but in the cauda equina, between L1 and L4 levels, it was the same as in the normal subjects $(55.8 \pm 7.8 \mathrm{~m} / \mathrm{s}$; NS). In the patient with a thoracic cord lesion due to radiation myelopathy the spinal cord motor conduction velocity was slowed $(25.4 \mathrm{~m} / \mathrm{s})$ and the cauda equina motor conduction velocity $(76 \mathrm{~m} / \mathrm{s})$ was in the high normal range. In case 2 motor conduction velocity was normal in the spinal cord and cauda equina, an observation consistent with the clinical findings.

\section{Discussion}

Motor conduction velocity in the cauda equina was similar to that found in human limb motor nerves. ${ }^{6}$ In the latter conduction velocity decreases approximately $6 \%$ between the $3 \mathrm{rd}$ and 8 th decades, but we

Table Results in patients with multiple sclerosis (MS) and radiation myelopathy

\begin{tabular}{|c|c|c|c|c|c|c|c|c|}
\hline \multirow[t]{2}{*}{ Case } & \multirow[t]{2}{*}{ Diagnosis } & \multirow[t]{2}{*}{ Age (yr) } & \multirow[t]{2}{*}{ Sex } & \multicolumn{3}{|c|}{$\begin{array}{l}\text { Latency to puborectalis or to tibialis } \\
\text { anterior }{ }^{*}(\mathrm{~ms})\end{array}$} & \multicolumn{2}{|c|}{$\begin{array}{l}\text { Motor conduction } \\
\text { velocity }(\mathrm{m} / \mathrm{s})\end{array}$} \\
\hline & & & & C6 & $L 1$ & $L 4$ & $C 6-L 1$ & $L 1-L 4$ \\
\hline $\begin{array}{l}1 \\
2 \\
3 \\
4^{*} \\
5 \\
6^{*}\end{array}$ & $\begin{array}{l}\text { MS } \\
\text { MS } \\
\text { MS } \\
\text { MS } \\
\text { MS } \\
\text { Radiation myelopathy }\end{array}$ & $\begin{array}{l}30 \\
45 \\
55 \\
65 \\
70 \\
60\end{array}$ & $\begin{array}{l}\mathbf{F} \\
\mathbf{M} \\
\mathbf{F} \\
\mathbf{F} \\
\mathbf{F} \\
\mathbf{M}\end{array}$ & $\begin{array}{l}15 \cdot 0 \\
10 \cdot 0 \\
13 \cdot 5 \\
33 \cdot 5 \\
13 \cdot 5 \\
31 \cdot 0\end{array}$ & $\begin{array}{r}4 \cdot 8 \\
3 \cdot 6 \\
5 \cdot 6 \\
17 \cdot 0 \\
4 \cdot 6 \\
17 \cdot 0\end{array}$ & $\begin{array}{r}3 \cdot 8 \\
2 \cdot 0 \\
4 \cdot 2 \\
15 \cdot 5 \\
2 \cdot 8 \\
15 \cdot 5\end{array}$ & $\begin{array}{l}39 \cdot 2 \\
75 \cdot 0 \\
43 \cdot 0 \\
24 \cdot 2 \\
43 \cdot 8 \\
25 \cdot 4\end{array}$ & $\begin{array}{l}70 \cdot 0 \\
57 \cdot 1 \\
54 \cdot 0 \\
50 \cdot 8 \\
47 \cdot 2 \\
76 \cdot 0\end{array}$ \\
\hline
\end{tabular}


observed no statistically significant effect of increasing age in the cord or cauda equina motor conduction velocity in our relatively small sample. Our stimulus electrodes, situated on the skin overlying the spinal cord or cauda equina, are several centimetres distant from the underlying excitable nervous tissue so that the precise point of stimulation of cord or nerve roots is not necessarily represented by the surface marking of the cathode. However, we presume this error is similar at the three stimulation sites so is eliminated during calculation of conduction velocity. Variations in length of the cord in different subjects, implicit in latency measurements. are normalised by calculation of conduction velocity (fig 2). Desmedt and Cheron ${ }^{7}$ found in cadaver dissections, that the measured length of the spinal cord from $\mathrm{T} 12$ to $\mathrm{C} 7$ was $13 \%$ less than the surface measurement of interspinous distances. Inspection of the cadaver spine cut in the sagittal plane illustrated by Desmedt and Cheron ${ }^{7}$ shows that this difference between surface-measured cord length, determined by surface markings of the spinous processes of $\mathrm{T} 12$ and $\mathrm{C} 7$ results from the horizontal orientation of the spinous process of $\mathrm{T} 12$, and the upwardly sloping orentation of that of $\mathrm{C} 7$. The latter is due to the normal cervico-thoracic lordosis. It is therefore possible that surface measurements of spinal length lead to an overestimate of the spinal motor conduction velocity by a factor of about $13 \%$. The mean spinal cord motor conduction velocity of our normal subjects would then be reduced to $58.6 \mathrm{~m} / \mathrm{s}$. Measurement of pyramidal tract conduction velocity estimated from scalp stimulation suggested a velocity of $48 \mathrm{~m} / \mathrm{s}$ between the motor cortex and the brachial cord segments. ${ }^{8}$

Our preliminary experiments revealed no change in latency when stimulating cord or cauda equina with the cathode or anode of the stimulating electrode held caudally. An explanation of this observation has been suggested to us in discussion with PA Merton. Cortical stimulation is best effected by anodal stimulation, ${ }^{2}$ perhaps because nerve fibres in the cortex are disposed perpendicular to the surface of the brain. In the spinal cord, cauda equina and peripheral nerve the nerve fibres are orientated parallel to the surface. Stimulation of excitable nervous tissue probably occurs at the site of exit of current and in the latter instance would thus occur at some point between the two electrodes. It is thus important to maintain a constant orientation of the stimulating electrode with respect to the structure to be investigated, and to use the distal electrode as the fixed point from which measurements are made. There is no theoretical reason why cord or cauda equina shquld be less susceptible to electrical stimulation than peripheral nerve or cortex, given a stimulus of appropriate amplitude and location. During transcutaneous stimulation of the motor cortex a larger amplitude motor response to C6 stimulation is produced by asking the subject to contract the muscle under test ${ }^{9}$ but we found no such consistent effect in our experiments on the cord and none in the cauda equina. We have not used a more rostral site of stimulation than $\mathrm{C6}$, preferring to avoid stimulating cord segments innervating the diaphragm. In addition, stimulation at a higher level in the neck would cause backward jerking of the neck from excitation of the neck extensor muscles and this might be uncomfortable or even hazardous. We have not used direct electrical stimulation of the cord in patients with heart disease, or with pacemakers.

We suggest that fastest motor conduction in the spinal cord represents transmission of a descending volley in the corticospinal tracts. Other descending pathways, for example of reticulospinal or rubrospinal tracts, might also be activated by spinal stimulation at $\mathrm{C} 6$ but these are unlikely to contribute to the fastest conducting component, although activity in these pathways might be important in the later components of the evoked muscle response (see fig 3). Although it is conceivable that antidromic conduction in the dorsal columns might reflexly activate lumbosacral spinal motoneurons this seems ruled out in our experiments by the latency measurements, which do not allow time for the interposition of another synaptic delay in the response mediated by C6 stimulation. Most of the nerve fibres in the human corticospinal tract are myelinated. ${ }^{10}$ Their diameters range from $1-22 \mu \mathrm{m}^{\prime \prime}$ but only about $2 \%$ of these fibres, corresponding to fibres originating from Betz cells in area 4 of motor cortex ${ }^{12}$ are greater than $11 \mu \mathrm{m}$ in diameter. ${ }^{11}$ Applying Hursch's conversion factor of $6,{ }^{13}$ these larger diameter fibres would be expected to conduct at velocities in the range we have recorded, suggesting that our results represent conduction in the corticospinal tracts. In the cat, conduction velocity in corticospinal fibres varies from 7 to $70 \mathrm{~m} / \mathrm{s}$, with peaks at 14 and $42 \mathrm{~m} / \mathrm{s}^{14}$ About $3 \%$ of corticospinal fibres in the cat conduct faster than $60 \mathrm{~m} / \mathrm{s} .^{13}$ In the central nervous system, the relation between myelinated fibre diameter and conduction velocity may not be linear through the whole range of diameters. Studies in the cat optic nerve suggest a higher value for Hursch's factor in the larger myelinated fibres than in the smaller. ${ }^{15}$

Experimental demyelination in the cat spinal cord results in slowed conduction, or conduction block. ${ }^{16}$ This is most severe with paranodal demyelination, but less marked if demyelination spares the architectural and electrical properties of the nodes of Ran- 
vier. ${ }^{17}$ Corticospinal conduction should therefore be slowed in patients with demyelination of this pathway. In our patients with spastic paraparesis, due to multiple sclerosis or to radiation myelitis, we found the spinal cord motor conduction velocity was reduced, except in case 2 in whom the clinical features suggested a brain stem lesion. Motor conduction in the cauda equina in all these patients was normal. This non-invasive method for measurement of motor conduction velocity in the human spinal cord may thus prove relevant in the diagnosis of patients with spinal cord disease, especially in multiple sclerosis, but possibly also in patients with suspected spinal canal tumours. Other neurophysiological measurements in clinical use, such as somatosensory evoked potential studies, depend on afferent pathways, are uncomfortable and technically complex, and have a relatively low yield of abnormality. Further, the major disability in most patients with spinal cord disorders, especially multiple sclerosis, is motor rather than sensory, and it is more appropriate to study the motor pathways. The technique is safe and lends itself to exploration of lateralised spinal cord lesions by the application of surface electrodes to leg muscles, although this excludes the lower sacral cord from the test. When combined with scalp stimulation it is thus now possible to explore the motor system at cortical, ${ }^{18}$ spinal cord, cauda equina and peripheral nerve levels. At cord and cauda equina levels stimulation at one site allows measurement of latencies in both legs, representing conduction in the motor pathways of both sides of the spinal cord.

We thank Professor PA Merton and Mr HB Morton for introducing us to electrical stimulation of the central nervous system, and for many entertaining discussions.

\section{References}

1 Merton PA, Morton HB. Stimulation of the cerebral cortex in the intact human subject. Nature 1980;285: 227.

${ }^{2}$ Merton PA, Morton HB, Hill DK, Marsden CD. Scope of a technique for electrical stimulation of human brain, spinal cord and muscle. Lancet 1982;2:597-600

${ }^{3}$ Sherrington CS. Notes on the arrangement of some motor fibres in the lumbosacral plexus. J Physiol (Lond) 1982;13:672-5.
${ }^{4}$ Snooks SJ, Henry MM, Swash M. Anorectal incontinence and rectal prolapse: differential assessment of the innervation to puborectalis and external anal sphincter muscles. Gut 1984; in press.

${ }^{5}$ McDonald WI. What is multiple sclerosis? Clinical criteria for diagnosis. In: Davison AN, Humphrey JH, Liversedge AL, McDonald WI, Porterfield JS, eds. Multiple Sclerosis Research. London: HMSO, 1975:1-8.

6 Rosenfalck P. Electromyography: sensory and motor conduction findings in normal subjects. Copenhagen: Rigshospitalet, 1975.

${ }^{7}$ Desmedt JE, Cheron G. Spinal and far-field components of human somatosensory evoked potentials to posterior tibial nerve stimulation analysed with oesophageal derivations and non-cephalic reference recording. Electroencephalogr Clin Neurophysiol 1983;56:635-51.

${ }^{8}$ Marsden CD, Merton PA, Morton HB. Percutaneous stimulation of spinal cord and brain: pyramidal tract conduction velocities in man. J Physiol (Lond) 1982;328: 6P.

${ }^{9}$ Marsden CD, Merton PA, Morton HB. Direct electrical stimulation of corticospinal pathways through the intact scalp in human subjects. In: Desmedt JE, ed. Motor Control Mechanisms in Health and Disease. New York: Raven Press, 1983:387-92.

${ }^{10}$ DeMyer W. Number of axons and myelin sheaths in the adult human medullary pyramids: study with silver impregnation and iron haematoxylin staining methods. Neurology (Minneap) 1959;9:42-7.

${ }^{11}$ Lasseck AM. The human pyramidal tract. IV. A study of the mature, myelinated fibres of the pyramid.J Comp Neurol 1942;76:217-25.

12 Brodal A. Neurological Anatomy in Relation to Clinical Medicine. London: Oxford University Press, 1981.

${ }^{13}$ Hursch JB. Conduction velocity and diameter of nerve fibres. Am J Physiol 1939;127:131-9.

${ }^{14}$ Lance JW, Manning RL. Origin of the pyramidal tract in the cat. J Physiol (Lond) 1954;124:385-99.

is Ogden TE, Miller TE. Studies of the optic nerve of the rhesus monkey: nerve fibre spectrum and physiological properties. Vision Res 1966;6:485-506.

${ }^{16}$ McDonald WI, Sears TA. The effects of experimental demyelination on conduction in the central nervous system. Brain 1970;93:583-98.

${ }^{17}$ Sears TA, Bostock H. Conduction failure in demyelination: is it inevitable? In: Waxman SG, Ritchie JM, eds. Demyelinating Diseases: Basic and Clinical Electrophysiology. Advances in Neurology Vol 31. New York: Raven Press, 1981:357-75.

${ }^{18}$ Cowan JMA, Dick JPR, Day BL, Rothwell JC, Thompson PD, Marsden CD. Abnormalities in central motor pathway conduction in multiple sclerosis. Lancet 1984;ii:304-7. 